\title{
Correction to: Data-based support for petroleum prospect evaluation
}

\author{
Summaya Mumtaz ${ }^{1}$ (D) $\cdot$ Irina Pene ${ }^{1} \cdot$ Adnan Latif $^{1} \cdot$ Martin Giese $^{1}$ \\ Published online: 9 October 2020 \\ (C) Springer-Verlag GmbH Germany, part of Springer Nature 2020
}

\section{Correction to: Earth Science Informatics https://doi.org/10.1007/s12145-020-00502-4}

\begin{abstract}
After publication, it was realized that our discussion of a certain dataset could be understood as a negative statement about that dataset's quality. This was unintentional and the corresponding passages and references to that dataset were removed. Moreover, the author names of the reference below were corrected.
\end{abstract}

Sun S.Q., Wan J. (2002) Geological analogs usage rates high in global survey. Oil Gas J 100(46):49-50

The Acknowledgments section of this article has been corrected also as follows:
Acknowledgements The authors would like to thank Equinor ASA, in particular Jens Grimsgaard for his support in negotiating access to reservoir data, and Vegard Sangolt for useful discussions. We are grateful to IHS Markit for supporting the project by granting access to their data set. This work was supported by the Norwegian Research Council via the SIRIUS Centre for Research Based Innovation, Grant Nr. 237898.

The original article has been corrected.

Publisher's note Springer Nature remains neutral with regard to jurisdictional claims in published maps and institutional affiliations.

The online version of the original article can be found at https://doi.org/ 10.1007/s12145-020-00502-4.

Summaya Mumtaz

summayam@ifi.uio.no

Irina Pene

pene@ifi.uio.no

Adnan Latif

adnanl@ifi.uio.no

Martin Giese

martingi@ifi.uio.no

1 SIRIUS Center for Scalable Data Access, University of Oslo,

Gaustadalléen 23B, 0373 Oslo, Norway 